\title{
Synthesis and characterization of novel poly(butylene succinate-co-2-methyl-1,3-propylene succinate)s
}

\author{
C.-H. Chen, C.-S. Yang, M. Chen", Y.-C. Shih, H.-S. Hsu, S.-F. Lu \\ Department of Materials and Optoelectronic Science, National Sun Yat-sen University, Kaohsiung 80424, Taiwan, \\ Republic of China
}

Received 5 September 2010; accepted in revised form 4 November 2010

\begin{abstract}
Poly(butylene succinate) (PBSu), poly(2-methyl-1,3-propylene succinate) (PMPSu), and PBSu-rich copolyesters were synthesized using an effective catalyst, titanium tetraisopropoxide. Measurements of intrinsic viscosity (1.20$1.28 \mathrm{dl} / \mathrm{g}$ ) and gel permeation chromatography demonstrated the success of the preparation of polyesters with high molecular weights. The compositions of the copolyesters were determined in three approaches from ${ }^{1} \mathrm{H}$ and ${ }^{13} \mathrm{C}$ NMR (nuclear magnetic resonance) analyses, and good agreement between the results was obtained. The distributions of the comonomers were found to be random from the spectra of carbonyl carbon. Their thermal properties were elucidated using a differential scanning calorimeter and a thermogravimetric analyzer. No marked difference exists among the thermal stabilities of these polyesters. However, the window between the glass transition and the melting temperatures becomes narrower with the increase in the concentration of 2-methyl-1,3-propylene succinate in the copolymers. Additionally, the cold crystallization ability decreases considerably. Finally, PMPSu is an amorphous homopolymer. Wide-angle X-ray diffractograms of isothermally crystallized copolyesters also follow the same trend.
\end{abstract}

Keywords: polymer synthesis, copolyesters, NMR, thermal properties, WAXS

\section{Introduction}

Biodegradable materials can be degraded to $\mathrm{CO}_{2}$, $\mathrm{CH}_{4}, \mathrm{H}_{2} \mathrm{O}$, or other natural substances by the action of enzymes and microorganisms. They offer viable solutions to solve environmental pollution caused by the worldwide disposal of used synthetic polymers in the last several decades. Among biodegradable polymers, aliphatic polyesters have received considerable attention [1]. Poly(butylene succinate) (PBSu) is a chemosynthetic polyester with a relatively high melting temperature $\left(T_{\mathrm{m}} \approx 113^{\circ} \mathrm{C}\right)$ and favorable mechanical properties, which are comparable with those of such widely used polymers as polyethylene and polypropylene [2]. Moreover, owing to the excellent processability of PBSu, it can be processed using conventional equipment.
In general, the degree of crystallinity, spherulite size and lamellar structure of aliphatic polyesters affect their biodegradation rates, because biodegradation initially occurs in the amorphous regions [3, 4]. The crystalline structure [5-9], and crystallization and melting behavior [10-18] of PBSu have been investigated extensively. PBSu has a relatively low biodegradation rate because of its high crystallization rate and high crystallinity. To promote the physical properties, extend the application field, and increase the biodegradability of PBSu, numerous approaches have been used, such as physical blending, copolymerization, or formation of composites. With respect to copolymers, the degradation rates of PBSu can be increased by incorporating small amounts of various diols [19-24] or

\footnotetext{
*Corresponding author, e-mail: mingchen@mail.nsysu.edu.tw
} (c) BME-PT 
diacids [24-28]; this is basically attributed to the reduced crystallinity.

Unlike PBSu, poly(propylene succinate) (PPSu) has an odd number of carbon atoms in the backbone. PPSu has gained increasing attention, because it has a higher biodegradation rate [29-32]. Papageorgiou and Bikiaris [33] have synthesized a series of poly(butylene succinate-co-propylene succinate)s (PBPSu) and have reported that the tensile strength and Young's modulus were very low and almost identical to those of the neat PPSu for PPSu-rich copolymers (50-90 mol\%). The decrease in the crystallinity of copolymers was attributed to the reduction in length of homopolymer sequences and the occurrence of defects. These copolyesters with a low degree of crystallinity and slower crystallization rate exhibited a higher biodegradation rate than PBSu. Recently, Chen et al. [34] also synthesized and characterized a series of PBSu-rich PBPSu copolyesters by combining PBSu with a high melting point and PPSu with high biodegradability. They also reported that incorporating propylene succinate units to PBSu not only narrows the window between the glass transition temperature $\left(T_{\mathrm{g}}\right)$ and $T_{\mathrm{m}}$, but also retards the cold crystallization ability, thereby lowering the crystallinity to a considerable extent.

In contrast with the high cost and the limited availability of 1,3-propanediol, 2-methyl-1,3-propanediol (MPD) became commercially available in the early 1990s. It is well recognized that the linearity and conformation of polymer backbone have a significant effect on the crystallization behavior of the polymer. The methyl group which MPD introduces into the polymer side chain helps to inhibit the crystallization of polyester resins [35-39]. The effects of MPD monomer on the physical properties of unsaturated [40-43] and isophthalate-based polyesters have been studied [44]. No prior investiga- tion of succinate involving MPD could be found in the literature. Furthermore, methyl substituent in the diol of PBSu-based biodegradable polyesters has not been probed.

In this work, PBSu, poly(2-methyl-1,3-propylene succinate) (PMPSu), and PBSu-rich copolyesters [poly(butylene succinate-co-2-methyl-1,3-propylene succinate), PBMPSu] with high molecular weight were synthesized. They were characterized by ${ }^{1} \mathrm{H}$ and ${ }^{13} \mathrm{C}$ Nuclear Magnetic Resonance (NMR) spectrometer, differential scanning calorimeter (DSC), thermogravimetric analyzer (TGA) and wideangle X-ray diffractometer (WAXD). ${ }^{13} \mathrm{C}$ NMR spectra were analyzed to evaluate the composition and the distribution of butylene succinate (BS) units and 2-methyl-1,3-propylene succinate (MS) units. The purpose of the present study is to examine the effect of methyl substituent on the cold crystallization of quenched polymers.

\section{Experimental}

\subsection{Materials}

1,4-Butanediol (BD) (Acros, 99\%, Waltham, MA, USA), MPD (Aldrich, 99\%, Louis, MO, USA) and succinic acid (SA) (Acros, 99\%) were used without purification. Titanium tetraisopropoxide (TTP) (Acros, 98+\%) was used as received. Other solvents in the analysis were also used without purification.

\subsection{Synthesis}

PBSu, PMPSu and PBSu-rich copolyesters were synthesized via a two-step esterification reaction in the melt. The reactor was a 11 stainless flask that was equipped with a magnetic agitator, an electric heater, a nitrogen inlet and outlet, a drain, a water cooling system and a condenser. The reaction mixture was charged into the reactor with a diols:diacid molar ratio of 1:1. TTP was used as a catalyst with a concentration of $0.1 \mathrm{~mol} \%$ based on the amount of

Table 1. Intrinsic viscosity, molecular weight, and thermal properties of synthesized polyesters

\begin{tabular}{|l|c|c|c|c|c|c|c|}
\hline \multicolumn{1}{|c|}{ Sample code } & $\begin{array}{c}\mathbf{\eta} \\
{[\mathbf{d l} / \mathbf{g}]}\end{array}$ & $\begin{array}{c}\overline{\mathbf{M}}_{\mathbf{n}} \\
{\left[\mathbf{1 0}^{\mathbf{4}} \mathbf{g} / \mathbf{m o l}\right]}\end{array}$ & $\begin{array}{c}\overline{\mathbf{M}}_{\mathbf{w}} \\
{\left[\mathbf{1 0}^{\mathbf{4}} \mathbf{g} / \mathbf{m o l}\right]}\end{array}$ & $\mathbf{P D I}^{\mathbf{a}}$ & $\begin{array}{c}\mathbf{T}_{\mathbf{g}} \\
{\left[{ }^{\circ} \mathbf{C}\right]}\end{array}$ & $\begin{array}{c}\mathbf{T}_{\mathbf{c c}} \\
{\left[{ }^{\circ} \mathbf{C}\right]}\end{array}$ & $\begin{array}{c}\mathbf{T}_{\mathbf{m}} \\
{\left[{ }^{\circ} \mathbf{C}\right]}\end{array}$ \\
\hline PBSu & 1.27 & 3.0 & 7.4 & 2.5 & -41.1 & -15.5 & 113.1 \\
\hline PBMPSu 95/5 & 1.23 & 2.7 & 7.3 & 2.7 & -39.9 & -3.0 & 107.4 \\
\hline PBMPSu 90/10 & 1.20 & 2.4 & 5.2 & 2.2 & -38.3 & -0.3 & 102.5 \\
\hline PBMPSu 80/20 & 1.28 & 3.1 & 9.7 & 3.1 & -37.8 & 12.2 & 91.6 \\
\hline PBMPSu 50/50 & 1.28 & 3.1 & 9.1 & 2.9 & -33.1 & - & $50.2^{\mathrm{b}}$ \\
\hline PMPSu & 1.24 & 4.0 & 12.0 & 3.0 & -30.9 & - & - \\
\hline
\end{tabular}

${ }^{\text {aPolydispersity index }}$

${ }^{\mathrm{b}}$ Specimen was kept at room temperature for more than 3 days 
diacid used. The first column of Table 1 shows the sample codes of copolyesters (PBMPSu), with the numerical values representing the feed ratios of the diols (BD/MPD). As an example, the synthesis of copolyester (PBMPSu 50/50) with equal amounts of diols is described as follows.

The reaction mixture of BD ( $45 \mathrm{~g} ; 0.5 \mathrm{~mol})$, MPD (45 g; $0.5 \mathrm{~mol}), \mathrm{SA}(118 \mathrm{~g} ; 1 \mathrm{~mol})$, and the TTP catalyst $(0.283 \mathrm{~g} ; 1.0 \mathrm{mmol})$ was charged into the polycondensation reactor. The mixture was purged with nitrogen and heated with an electrical heater that was placed around the reactor. The temperature of the reactor was raised to $150^{\circ} \mathrm{C}$ to melt the acid component completely. Thereafter, the temperature was gradually increased to $190^{\circ} \mathrm{C}$ at $10^{\circ} \mathrm{C} / \mathrm{h}$. The water byproduct formed during the first stage was collected using a condenser. The condenser was kept at $100^{\circ} \mathrm{C}$ by an electrical heater for the separation of water from the monomers. The volume of water collected was $80 \mathrm{~mol} \%$ of the theoretical value. In the second stage of the reaction, the pressure was slowly reduced to below 1 Torr $(1$ Torr $=$ $133 \mathrm{~Pa}$ ) and the temperature was increased to $220^{\circ} \mathrm{C}$ after $3 \mathrm{~h}$ of reaction. This condition was maintained for about $20 \mathrm{~h}$ to enable further the reactions of polycondensation and transesterification until the torque of magnetic agitator reached $80 \%$ of the meter to read. The synthesized polyester was dissolved in chloroform and precipitated into ten times the amount of vigorously stirred ice-cooled methanol. Then, the precipitate was filtered, washed with methanol and dried at reduced pressure condition at room temperature $(R T)$. The other three copolyesters (PBMPSu 95/5, PBMPSu 90/10, and PBMPSu 80/20) as well as PBSu and PMPSu homopolymers were synthesized by the same procedures. Ivory white, pale brown or transparent polyesters were finally obtained.

\subsection{Measurement of molecular weights}

Gel permeation chromatography (GPC) was performed at $40^{\circ} \mathrm{C}$ using a Waters GPC-150CV and a Waters hexafluoroisopropanol (HFIP) column (Milford, MA, USA). The flow rate of the eluent, HFIP, was $1.0 \mathrm{ml} / \mathrm{min}$. The number average $\left(\bar{M}_{\mathrm{n}}\right)$ and weight average $\left(\overline{M_{\mathrm{w}}}\right)$ molecular weights of each polyester were calculated using a calibration curve, which was obtained using eight poly(methyl methacrylate) standards having low polydispersity indices.

Purified polyester samples were dissolved in $60 / 40 \mathrm{w} / \mathrm{w}$ phenol/1,1,2,2-tetrachloroethane solution. The solution viscosities of the polyesters at $30^{\circ} \mathrm{C}$ were measured using an Ubbelohde viscometer. The intrinsic viscosity, $(\eta)$, of each polyester was determined from measurements at five solution concentrations.

\subsection{NMR analyses}

NMR spectra of $d$-chloroform solutions were recorded with tetramethylsilane as the reference standard using a Varian UNITY INOVA-500 NMR (Santa Clara, CA, USA) at 295.5 K. ${ }^{1} \mathrm{H}$ NMR spectra were analyzed to determine the compositions of the copolyesters. To perform quantitative ${ }^{13} \mathrm{C}$ NMR measurement, it is important to take into account the difference of spin-lattice relaxation time among different carbons. ${ }^{13} \mathrm{C}$ NMR was conducted using a 30 -s pulse cycle [34] to determine both the composition and the ester sequence distribution in these copolyesters.

\subsection{Measurement of thermal properties}

Compressed films with a thickness of around $0.2 \mathrm{~mm}$ were made and then dried in vacuum overnight at $R T$ before use. A specimen with a diameter of $6 \mathrm{~mm}$ and a weight of around $4 \mathrm{mg}$ was cut from a film and sealed in an aluminum pan. The thermal properties of the polyesters were analyzed using a Perkin-Elmer Pyris 1 DSC (Waltham, MA, USA), equipped with a refrigerating system (Pyris Intracooler 2P). DSC was calibrated with deionized water and indium and was also calibrated using the heat of fusion of indium. The specimen was heated at a rate of $20^{\circ} \mathrm{C} / \mathrm{min}$ to $50^{\circ} \mathrm{C}$ above its $T_{\mathrm{m}}$, which was held for $5 \mathrm{~min}$ to eliminate the thermal history. Subsequently, the specimen was quenched with liquid nitrogen, and then heated at a rate of $10^{\circ} \mathrm{C} / \mathrm{min}$ to above its $T_{\mathrm{m}}$. The $T_{\mathrm{g}}$, cold crystallization temperature $\left(T_{\mathrm{cc}}\right)$ and $T_{\mathrm{m}}$ were detected during the heating process.

\subsection{Measuring thermal stability}

Thermal experiments were performed using a TA 2050 TGA (New Castle, DE, USA). Nitrogen gas was the purge gas with a flow rate of $50 \mathrm{ml} / \mathrm{min}$. A 
specimen lighter than $10 \mathrm{mg}$ was heated at a rate of $10^{\circ} \mathrm{C} / \mathrm{min}$ from $R T$ to $800^{\circ} \mathrm{C}$. Weight loss curves and their derivatives were obtained to compare the relative thermal stabilities of the synthesized polyesters.

\subsection{WAXD measurements}

Specimens with a thickness of around $0.5 \mathrm{~mm}$, following completely isothermal crystallization at $R T$ (room temperature) or at a temperature of $10-12^{\circ} \mathrm{C}$ below their respective $T_{\mathrm{m}}$ values, were prepared using a heating stage (Linkam THMS-600) (Tadworth, Surrey, UK). X-ray diffractograms were obtained using a Siemens D5000 diffractometer (Bruker AXS Inc., Madison, WI, USA) with Ni-filtered $\mathrm{Cu} \mathrm{K}$ radiation $(\lambda=0.1542 \mathrm{~nm}, 40 \mathrm{kV}, 30 \mathrm{~mA})$ at a scanning rate of $1 \% \mathrm{~min}$. Measurements were made at $R T$.

\section{Results and discussion}

\subsection{Molecular weights and distribution}

The intrinsic viscosities of these polyesters ranged from 1.20 to $1.28 \mathrm{dl} / \mathrm{g}$, as listed in column 2 of Table 1. $\bar{M}_{\mathrm{n}}$ and $\bar{M}_{\mathrm{w}}$ values of these polyesters were between $2.4 \cdot 10^{4}$ and $4.0 \cdot 10^{4} \mathrm{~g} / \mathrm{mol}$ and between $5.2 \cdot 10^{4}$ and $1.2 \cdot 10^{5} \mathrm{~g} / \mathrm{mol}$, respectively, and their polydispersity indices (PDI) ranged from 2.2 to 3.1 , as shown in columns $3-5$ of Table 1 . These wide PDI values may be due to the transesterification at $220^{\circ} \mathrm{C}$ for about $20 \mathrm{~h}$. In this work, PBSu, PMPSu, and PBMPSu copolyesters were synthesized using an effective catalyst, TTP, without the addition of any heat stabilizer. The molecular weights of these synthesized polyesters are high enough. Therefore, they could be made into films for the subsequent works.

\subsection{Copolyester composition and sequence distribution}

Figure 1 displays the ${ }^{1} \mathrm{H}$ NMR spectrum of PBMPSu $50 / 50$ copolymer and the peak assignments. The two chemical shifts at $4.09-4.15$ and 1.68$1.74 \mathrm{ppm}$ are associated with the methylene protons $\alpha\left(\mathrm{H}_{1}\right)$ and $\beta\left(\mathrm{H}_{2}\right)$ bonded to the ester oxygen in the BS units. The chemical shift of the protons of the succinic moiety $\left(\mathrm{H}_{3}\right)$ appears at 2.61-2.66 ppm, while those of the $\mathrm{H}_{4}, \mathrm{H}_{5}$ and $\mathrm{H}_{7}$ protons derived from the MPD monomer are at 4.01-4.06 ppm (methylene, doublet), 2.12-2.22 ppm (methine,
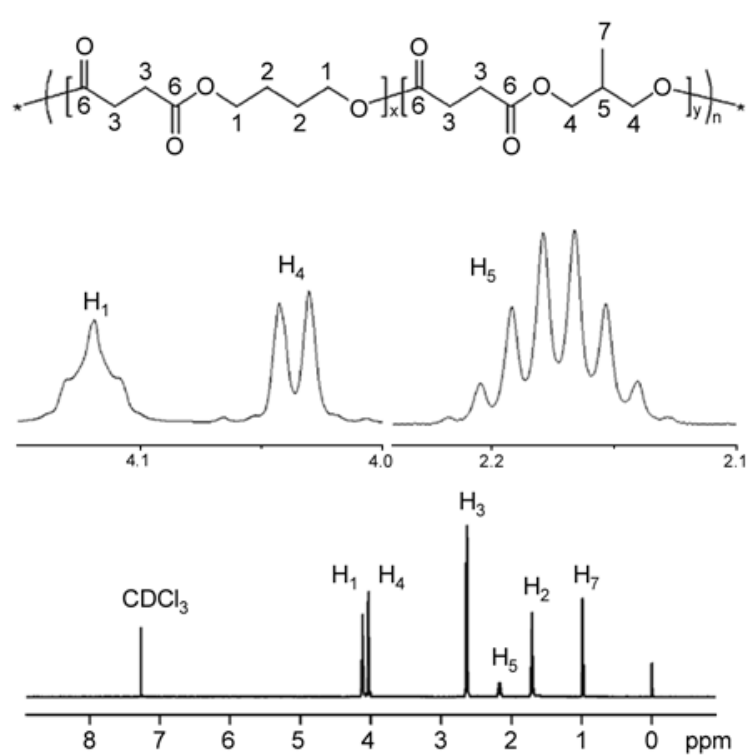

Figure 1. ${ }^{1} \mathrm{H}$ NMR spectrum of PBMPSu 50/50 and peak assignments

octet) and 0.97-1.01 ppm (methyl, doublet, not shown here), respectively. The composition of this copolyester was evaluated from the relative integration areas of the proton peaks of BS and MS units. The mole percent ratio of BS/MS in PBMPSu 50/50 was 50.0/50.0, as presented in the third column of Table 2. Rows $1-3$ of the same column show the compositions of the other copolymers. An expanded view of the proton peaks is presented in the inset spectra in Figure $1 . \mathrm{H}_{1}, \mathrm{H}_{4}$ and $\mathrm{H}_{5}$ appear as triplet, doublet and octet, respectively.

Figure 2 shows the ${ }^{13} \mathrm{C}$ NMR spectrum of PBMPSu $50 / 50$. For BS units, the chemical shifts of the carbons $\alpha$ and $\beta$ bonded to the ester oxygen are located at $64.05-64.20\left(\mathrm{C}_{1}\right)$ and $25.10-25.20\left(\mathrm{C}_{2}\right) \mathrm{ppm}$, respectively. The three chemical shifts at $65.85-$ $66.00\left(\mathrm{C}_{4}\right), 32.27-32.37\left(\mathrm{C}_{5}\right)$ and $13.69-13.77$ $\left(\mathrm{C}_{7}\right) \mathrm{ppm}$ are associated with carbons derived from the MPD monomer. The chemical shifts of the ethylene carbons and the carbonyl carbons of the succinic moiety are at 28.86-29.00 $\left(\mathrm{C}_{3}\right)$ and 172.06$172.28\left(\mathrm{C}_{6}\right) \mathrm{ppm}$, respectively. The composition was determined from the relative integration areas of the $\mathrm{C}_{1}$ and $\mathrm{C}_{4}$ peaks. The mole percent ratio of BS/MS in PBMPSu 50/50 was 49.6/50.4, as presented in the fourth column of Table 2. The compositions of the other three copolymers are tabulated in rows $1-3$ of the same column.

A close-up view of the ${ }^{13} \mathrm{C}$ NMR spectrum of PBMPSu 50/50 shows that the carbonyl carbons 


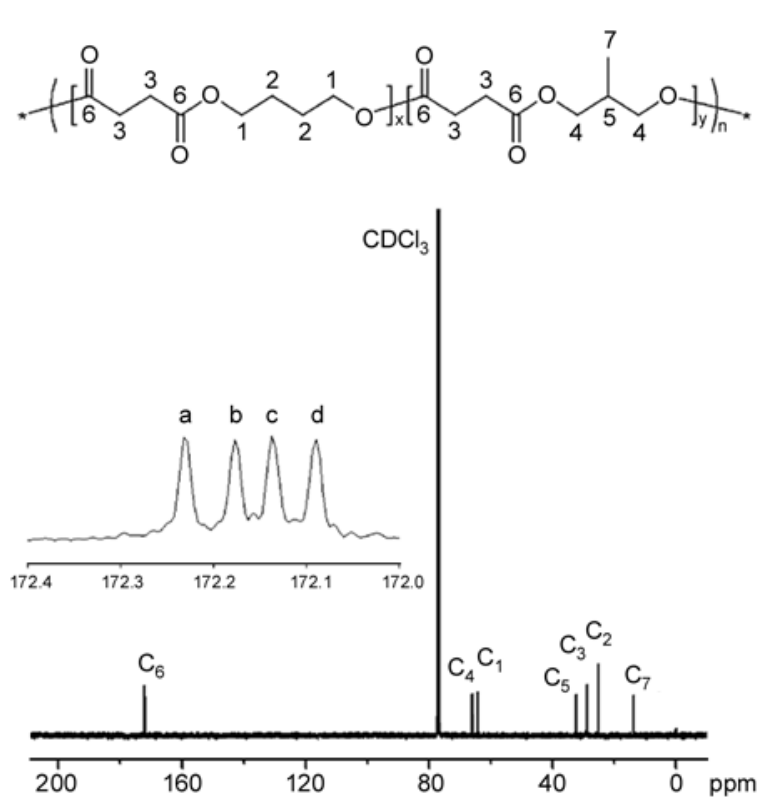

Figure 2. ${ }^{13} \mathrm{C}$ NMR spectrum of PBMPSu 50/50 and peak assignments

$\left(\mathrm{C}_{6}\right)$ are split into four peaks, as shown in the inset spectrum in Figure 2. The peak $\mathrm{C}_{6 \mathrm{a}}$ is assigned to the carbonyl carbons with butylene groups on both sides of the succinic ester, abbreviated as BSB. The assigned $\mathrm{C}_{6 \mathrm{~b}}, \mathrm{C}_{6 \mathrm{c}}$, and $\mathrm{C}_{6 \mathrm{~d}}$ peaks represent the carbonyl carbons of the BSM-B side, BSM-M side, and MSM structures, respectively (where B denotes the $\mathrm{BD}$ unit, $\mathrm{S}$ represents the succinate unit, and $\mathrm{M}$ is the MPD unit). Figure 3 presents the expanded spectra of the carbonyl carbons of all synthesized polyesters. It is obvious that the slight variation in chemical shifts of these split peaks is caused by the difference among the chemical environment; therefore, the integration areas can be employed to characterize the chemical microstructures of these copolyesters.

The total areas of $\mathrm{C}_{6 \mathrm{a}}, \mathrm{C}_{6 \mathrm{~b}}, \mathrm{C}_{6 \mathrm{c}}$, and $\mathrm{C}_{6 \mathrm{~d}}$ peaks were normalized to unity for each copolyester, and the percentage values of each peak area are presented in columns 5-8 of Table 2 under the subtitles of BSB, BSM-B side, BSM-M, side and MSM. Two peaks $\left(\mathrm{C}_{6 \mathrm{~b}}\right.$ and $\mathrm{C}_{6 \mathrm{c}}$ ) of equal intensity were observed from the unequivalent carbonyl carbons in the mixed diester sequence BSM. Three possible triad sequences, BSB, BSM, and MSM, of copolyesters were then evaluated from the normalized areas, and tabulated in columns $9-11$ of the Table 2 . In the case of PBMPSu 50/50, $P(\mathrm{BSB}), P(\mathrm{BSM})$, and $P(\mathrm{MSM})$ were $25.0,50.2$ and $24.8 \mathrm{~mol} \%$, respectively, as presented in the fourth row of Table 2 . The

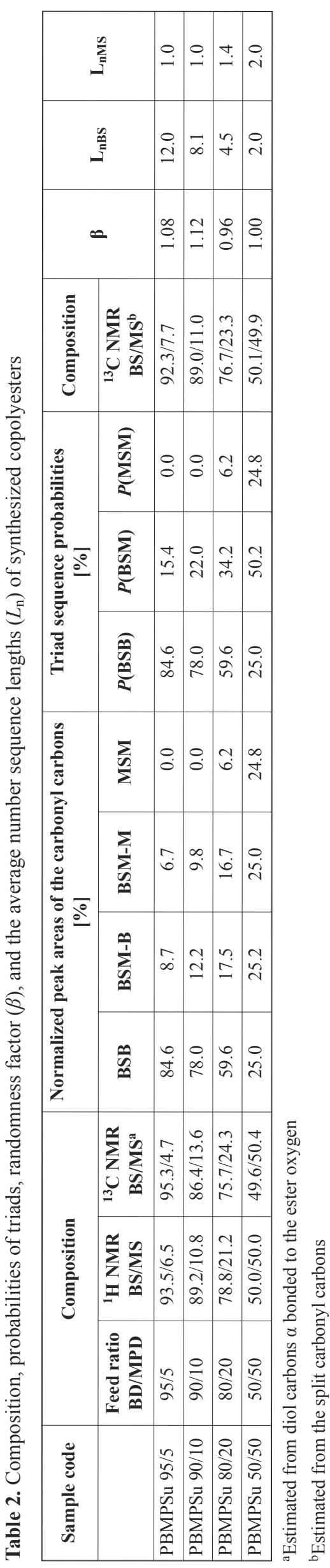



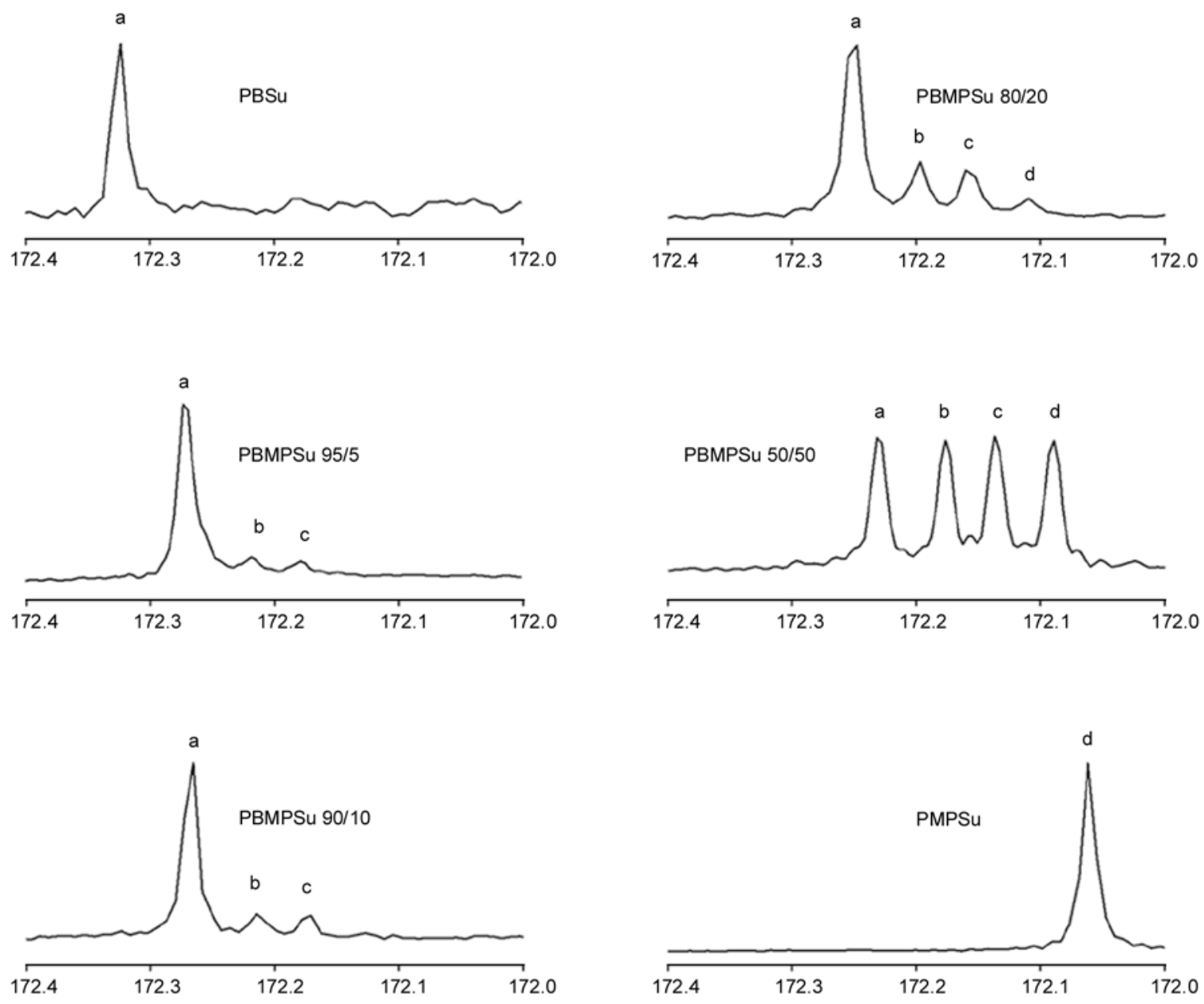

Figure 3. Enlarged ${ }^{13} \mathrm{C}$ NMR spectra of the carbonyl carbons $\left(\mathrm{C}_{6}\right)$ in the succinate units of all synthesized polyesters

$\mathrm{BS} \%$ and $\mathrm{MS} \%$ of copolyesters are given by Equations (1) and (2):

$\mathrm{BS} \%=P_{\mathrm{BS}}=P(\mathrm{BSB})+\frac{P(\mathrm{BSM})}{2}$
$\mathrm{MS} \%=P_{\mathrm{MS}}=P(\mathrm{MSM})+\frac{P(\mathrm{BSM})}{2}$

where $P_{\mathrm{BS}}$ and $P_{\mathrm{MS}}$ are the molar fractions of BS and MS units, respectively. This copolyester had $50.1 \mathrm{~mol} \%$ BS units and $49.9 \mathrm{~mol} \% \mathrm{MS}$ units. Column 12 of Table 2 displays the mole percent ratio of BS/MS of the other copolyesters. The agreement of composition among these three methods is good in this study, as shown in Table 2.

The randomness $B$ of the copolymer [34, 45-49] is given by $B=P(\mathrm{BSM}) /\left(2 P_{\mathrm{BS}} \cdot P_{\mathrm{MS}}\right)$. Copolyesters synthesized by polycondensation have usually been considered to have a random distribution. This expectation is due to the relatively equal reactivity of the comonomers and the random transesterification during the polycondensation process. For total randomness of a copolymer, $B$ is one. The calculated $B$ values of PBMPSu 95/5, 90/10, 80/20, and $50 / 50$ were $1.08,1.12,0.96$, and 1.00 , respectively, as presented in column 13 of Table 2. The distribution of BS and MS units in these copolyesters can be regarded as random. The reactivities of $\mathrm{BD}$ and MPD with SA can be assumed to not differ by much. The average number sequence lengths [33, $45,48-50]$ of $\mathrm{BS}$ and $\mathrm{MS}$ units are $L_{\mathrm{nBS}}=$ $2 P_{\mathrm{BS}} / P(\mathrm{BSM})$ and $L_{\mathrm{nMS}}=2 P_{\mathrm{MS}} / P(\mathrm{BSM})$, respectively. In the case of PBMPSu 50/50, both values were 2.0. These values are tabulated in the last two columns of Table 2 . The values of $L_{\mathrm{nBS}}$ for PBMPSu $95 / 5,90 / 10$, and $80 / 20$ were $12.0,8.1$, and 4.5 , respectively. The $L_{\mathrm{nBS}}$ value decreases as the amount of MS unit increases along the polymer chain. 


\subsection{Thermal properties}

Figure 4 shows DSC heating curves of quenched polyesters. PBSu has the lowest $T_{\mathrm{g}}$ at $-41.1^{\circ} \mathrm{C} . T_{\mathrm{g}}$ value gradually increases as the moiety of the MS units increases. It ranges from -41.1 to $-30.9^{\circ} \mathrm{C}$, as listed in column 6 in Table 1. The copolyesters had intermediate $T_{\mathrm{g}}$ between those of the parent homopolyesters. Such a $T_{\mathrm{g}}$ increment is attributed to a decrease in the chain flexibility by incorporating MS units. All of these copolyesters exhibited a single $T_{\mathrm{g}}$ rather than two $T_{\mathrm{g}} \mathrm{s}$, for possible blocks of PBSu and PMPSu. Moreover, all of these copolyesters had $B$ (randomness parameter) values of about 1.0 , which were obtained from the ${ }^{13} \mathrm{C}$ NMR analysis (Table 2). These results demonstrate that the comonomer placement in these copolymers was essentially random. The $T_{\mathrm{g}}$ value of PBMPSu is slightly higher than that of the corresponding PBPSu [34]. However, the $T_{\mathrm{g}}$ value of PMPSu is $0.4^{\circ} \mathrm{C}$ less than that of PPSu [34]. This contradictory result may be due to the difference in molecular weight. It seems that the methyl substituted effect on the $T_{\mathrm{g}}$ value is not obvious.

A cold crystallization peak was observed for PBSu and PBSu-rich PBMPSu copolyesters, as presented in Figure 4. The peak temperature of cold crystallization $\left(T_{\mathrm{cc}}\right)$ occurs at $-15.5^{\circ} \mathrm{C}$ for $\mathrm{PBSu}$, and this peak is sharper and earlier than those of the other three copolyesters, suggesting that the cold crystallization rate of the PBSu homopolymer markedly exceeds that of the other copolyesters. For PBMPSu $95 / 5,90 / 10$, and $80 / 20, T_{\mathrm{cc}}$ moves from -3.0 , through -0.3 to $12.2^{\circ} \mathrm{C}$ (see the penultimate column in Table 1) and the corresponding peak becomes lower and broader, as shown in Figure 4. These $T_{\mathrm{cc}}$

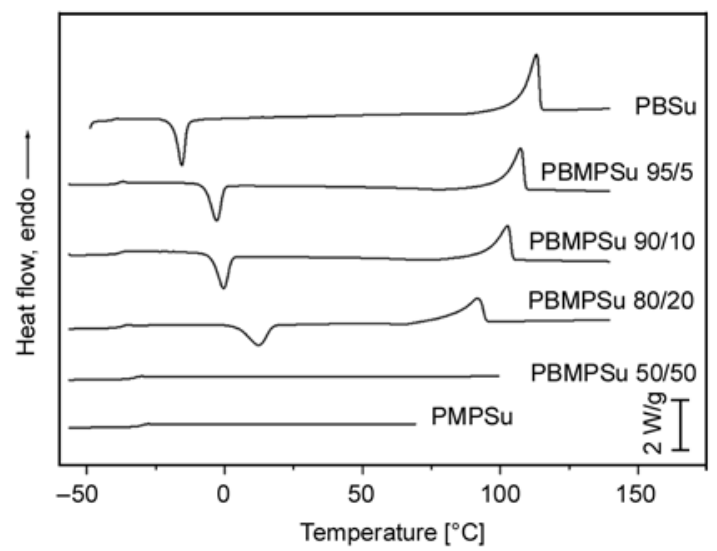

Figure 4. DSC thermograms of quenched polyesters at a heating rate of $10^{\circ} \mathrm{C} / \mathrm{min}$ values are $4 \sim 6^{\circ} \mathrm{C}$ higher than those of the corresponding PBPSu [34]. No cold crystallization is revealed by the curves of PBMPSu 50/50 and PMPSu. Clearly, incorporating minor MS units into PBSu reduced the cold crystallization rate of quenched specimens. Accordingly, the intensity of the melting peak fell and the corresponding $T_{\mathrm{m}}$ declined from 113.1 to $91.6^{\circ} \mathrm{C}$, as indicated in the final column of Table 1 . The enthalpy of melting $\left(\Delta H_{\mathrm{m}}\right)$ was evaluated and the degree of crystallinity was calculated by dividing $\Delta H_{\mathrm{m}}$ by $210 \mathrm{~J} / \mathrm{g}$ [16]. The degrees of crystallinity were $35.0 \%$ for PBSu, $32.8 \%$ for PBMPSu 95/5, 28.1\% for PBMPSu $90 / 10$, and $25.0 \%$ for PBMPSu $80 / 20$. These values were only $0.3 \%$ less than the degrees of crystallinity of the corresponding PBPSu 95/5 and 90/10 copolymers.

Comparing the values of $T_{\mathrm{cc}}$ and $T_{\mathrm{m}}$ between PBMPSu and PBPSu [34], the results indicate that the effect of methyl substitution on the $T_{\mathrm{m}}$ value is little. The reason is due to the melting-recrystallization-remelting behavior $[11,12,15,17]$ of PBSu-rich copolymers during the heating process. In the case of PBMPSu 50/50, the $T_{\mathrm{m}}$ value was $50.2^{\circ} \mathrm{C}$, when the specimen was maintained at $R T$ for more than three days. No melting phenomenon was detected for PMPSu homopolymer even after holding at different subzero temperatures for a long period. On the contrary, PPSu had a melting temperature at $55.6^{\circ} \mathrm{C}$ [34]. The effect of methyl substitution on retarding crystallization becomes more evident for neat PMPSu.

\subsection{Thermal stability}

Figure 5 plots the weight loss curves as functions of temperature for all of the polyesters used in this investigation in flowing nitrogen at a heating rate of $10^{\circ} \mathrm{C} / \mathrm{min}$. For brevity, the derivative curves of weight loss have not been shown here. At temperatures below $240^{\circ} \mathrm{C}$, these specimens appear to be stable; they exhibit detectable weight loss only above $242^{\circ} \mathrm{C}$ (defined as $T_{\text {start }}$ from the derivative curve of weight loss). $T_{\text {loss } 2 \%}$ is denoted as the temperature at a weight loss of $2 \%$ from the weight loss curve, and $T_{\max }$ represents the temperature with the greatest slope from the weight loss curve. The average values of $T_{\text {start, }}, T_{\text {loss } 2 \%}$, and $T_{\max }$ were $244.4 \pm 1.8$, $298.8 \pm 3.9$, and $404.5^{\circ} \mathrm{C} \pm 5.4^{\circ} \mathrm{C}$, respectively. These polyesters exhibited no significant difference or 


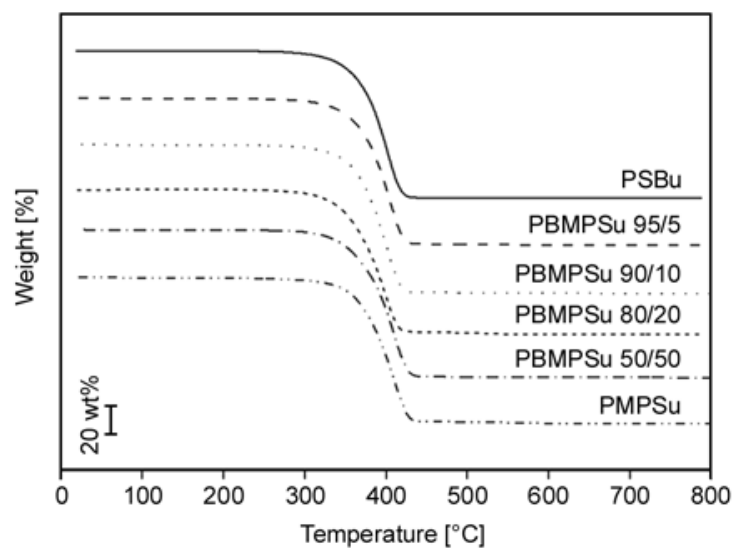

Figure 5. Thermogravimetric traces of polyesters at a heating rate of $10^{\circ} \mathrm{C} / \mathrm{min}$ under nitrogen

trend in these three temperature parameters because they degraded via the same cyclization degradation mechanism around the succinate groups. Similar results have been reported for the other series of aliphatic copolyesters [23, 34, 45, 49]. The values of $T_{\text {loss } 2 \%}$ are well above $220^{\circ} \mathrm{C}$, the temperature of the last step of synthesis. It can be assumed that no appreciable thermal degradation occurred during polycondensation; therefore, there is no demand to use a heat stabilizer during the synthesis of these polyesters. For PMPSu, the values of $T_{\text {start }}$ and $T_{\text {loss } 2 \%}$ were 243.3 and $293.4^{\circ} \mathrm{C}$, respectively, which were $\sim 8^{\circ} \mathrm{C}$ lower than those of PPSu [34]. It may be due to the reason that PMPSu is an amorphous polymer.

\subsection{Wide angle $X$-ray diffraction patterns}

Figure 6 displays WAXD patterns of PBSu, PMPSu, and PBSu-rich PBMPSu copolyesters that were isothermally crystallized at $10-12^{\circ} \mathrm{C}$ below their respective $T_{\mathrm{m}}$ values. The unit cell of the crystalline PBSu $\alpha$ form is monoclinic [5-9], and the diffraction peaks from the (020) and (110) planes are detected at $2 \theta \approx 19.6$ and $22.7^{\circ}$, respectively. All PBSu-rich copolyesters have diffraction peaks of the PBSu $\alpha$ form, revealing only one crystalline form. As the proportion of the MS units increases, the intensity of the diffraction peaks from the (020) and (110) planes becomes weaker and the width at half-maximum peak increases gradually. The mean crystal sizes $L_{\mathrm{hkl}}$, perpendicular to the $(h k l)$ plane, can be estimated with the familiar Scherrer equation, as follows [51]:

$L_{\mathrm{hkl}}=\frac{K \lambda}{\beta_{0} \cos \theta}$

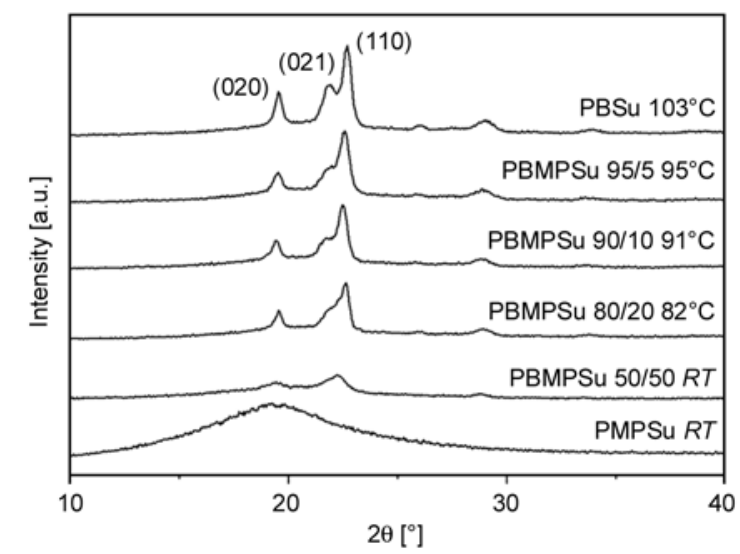

Figure 6. WAXD patterns from polyesters crystallized at the indicated temperatures

where $\beta_{0}$ is the breath at half-maximum peak corrected for instrumental broadening and $K$ denotes the Scherrer factor. $L_{\mathrm{hkl}}$ was strongly dependent on the peak broadening $\left(\beta_{0}\right)$. However, the numerical values obtained from Equation (3) are not accurate because of the prevalence of lattice distortions. Figure 6 shows that the sizes or the lamellar thickness of the crystals declines with increasing the MS amounts, indicating less crystalline order in copolymers. PMPSu shows amorphous scattering. The results of the WAXD patterns and DSC heating curves reveal that incorporation of MS units into PBSu markedly inhibit the crystallization behavior of the resultant polymers.

\section{Conclusions}

PBMPSu copolyesters were synthesized in a random sequence, as evidenced by a single $T_{\mathrm{g}}$ and a randomness value of around 1.0. Their intrinsic viscosities (1.20-1.28 dl/g) and the relative molecular weights are high enough to demonstrate that the synthesis of these polyesters was successful even without the use of stabilizers, and that they can be cast into films without complications. The compositions of the copolyesters were evaluated from three methods based on the relative areas of the proton peaks under BS and MS units, the carbon peaks $\alpha$ bonded to the ester oxygen, and the split peaks of carbonyl carbons. The results of these three approaches are in good agreement. The incorporation of MS units to PBSu not only narrows the window between $T_{\mathrm{g}}$ and $T_{\mathrm{m}}$, but also retards the cold crystallization ability, thereby lowering the degree of crystallinity to a considerable extent. Comparing 
with PBPSu copolyesters, this retarding is more efficient in PBMPSu copolyesters, which have methyl substituents on the main chain. The WAXD patterns of melt-crystallized specimens also indicate that the incorporation of MS units into PBSu markedly inhibits the crystallinity of the resultant copolymer, and becomes amorphous for PMPSu. However, the thermal stability of these polyesters does not vary markedly.

\section{Acknowledgements}

The authors would like to thank Mr. C.L. Lin at Chung Shan Institute of Science and Technology for his help in the GPC experiments. The financial support of the National Science Council (Grant NSC 97-2221-E-110-033) is also acknowledged.

\section{References}

[1] Mochizuki M., Hirami M.: Structural effects on the biodegradation of aliphatic polyesters. Polymers for Advanced Technologies, 8, 203-209 (1997).

DOI: 10.1002/(SICI)1099-1581(199704)8:4<203::AIDPAT627>3.0.CO;2-3

[2] Ishioka R., Kitakuni E., Ichikawa Y.: Aliphatic polyesters: 'Bionolle'. in 'Biopolymers' (eds.: Doi Y., Steinbüchel A.) Wiley, Weinheim, Vol 4, 275-297 (2002). DOI: 10.1002/3527600035.bpol4010

[3] Kumagai Y., Kanesawa Y., Doi Y.: Enzymatic degradation of microbial poly(3-hydroxybutyrate) films. Makromolecular Chemistry and Physics, 193, 53-57 (1992). DOI: $10.1002 /$ macp.1992.021930105

[4] Abe H., Doi Y., Aoki H., Akehata T.: Solid-state structures and enzymatic degradabilities for melt-crystallized films of copolymers of (R)-3-hydroxybutyric acid with different hydroxyalkanoic acids. Macromolecules, 31, 1791-1797 (1998).

DOI: $10.1021 / \mathrm{ma} 971559 \mathrm{v}$

[5] Ichikawa Y., Kondo H., Igarashi Y., Noguchi K., Okuyama K., Washiyama J.: Corrigendum to 'Crystal structures of $\alpha$ and $\beta$ forms of poly(tetramethylene succinate)'. Polymer, 42, 847 (2001).

DOI: $\underline{10.1016 / \mathrm{S} 0032-3861(00) 00390-6}$

[6] Ichikawa Y., Suzski J., Washiyama J., Moteki Y., Noguchi K., Okuyama K.: Strain-induced crystal modification in poly(tetramethylene succinate). Polymer, 35, 3338-3339 (1994).

DOI: 10.1016/0032-3861(94)90144-9

[7] Ichikawa Y., Suzski J., Washiyama J., Moteki Y., Noguchi K., Okuyama K.: Crystal transition mechanisms in poly(tetramethylene succinate). Polymer Journal, 27, 1230-1238 (1995).

DOI: $10.1295 /$ polymj.27.1230
[8] Ihn K. J., Yoo E. S., Im S. S.: Structure and morphology of poly(tetramethylene succinate) crystals. Macromolecules, 28, 2460-2464 (1995).

DOI: $10.1021 / \mathrm{ma} 00111 \mathrm{a} 045$

[9] Ichikawa Y., Kondo H., Igarashi Y., Noguchi K., Okuyama K., Washiyama J.: Crystal structures of $\alpha$ and $\beta$ forms of poly(tetramethylene succinate). Polymer, 41, 4719-4727 (2000).

DOI: 10.1016/S0032-3861(99)00659-X

[10] Miyata T., Masuko T.: Crystallization behaviour of poly(tetramethylene succinate). Polymer, 39, 13991404 (1998).

DOI: 10.1016/S0032-3861(97)00418-7

[11] Yoo E. S., Im S. S.: Melting behavior of poly(butylene succinate) during heating scan by DSC. Journal of Polymer Science Part B: Polymer Physics, 37, 13571366 (1999).

DOI: 10.1002/(SICI) 1099-0488(19990701)37:13< 1357::AID-POLB2>3.0.CO;2-Q

[12] Yasuniwa M., Satou T.: Multiple melting behavior of poly(butylene succinate). I. Thermal analysis of meltcrystallized samples. Journal of Polymer Science Part B: Polymer Physics, 40, 2411-2420 (2002). DOI: $10.1002 /$ polb. 10298

[13] Qiu Z. B., Komura M., Ikehara T., Nishi T.: DSC and TMDSC study of melting behaviour of poly(butylene succinate) and poly(ethylene succinate). Polymer, 44, 7781-7785 (2003).

DOI: $10.1016 /$ j.polymer.2003.10.045

[14] Qiu Z., Fujinami S., Komura M., Nakajima K., Ikehara T., Nishi T.: Nonisothermal crystallization kinetics of poly(butylene succinate) and poly(ethylene succinate). Polymer Journal, 36, 642-646 (2004).

DOI: $10.1295 /$ polymj.36.642

[15] Yasuniwa M., Tsubakihara S., Satou T., Iura K.: Multiple melting behavior of poly(butylene succinate). II. Thermal analysis of isothermal crystallization and melting process. Journal of Polymer Science Part B: Polymer Physics, 43, 2039-2047 (2005). DOI: 10.1002/polb.20499

[16] Papageorgiou G. Z., Bikiaris D. N.: Crystallization and melting behavior of three biodegradable poly(alkylene succinates). A comparative study. Polymer, 46, 1208112092 (2005).

DOI: $10.1016 /$ j.polymer.2005.10.073

[17] Wang X. H., Zhou J. J., Li L.: Multiple melting behavior of poly(butylene succinate). European Polymer Journal, 43, 3163-3170 (2007).

DOI: $10.1016 /$ j.eurpolymj.2007.05.013

[18] Papageorgiou G. Z., Achilias D. S., Bikiaris D. N.: Crystallization kinetics of biodegradable poly(butylene succinate) under isothermal and non-isothermal conditions. Macromolecular Chemistry and Physics, 208, 1250-1264 (2007).

DOI: $\underline{10.1002 / \mathrm{macp} .200700084}$ 
[19] Mochizuki M., Mukai K., Yamada K., Ichise N., Murase S., Iwaya Y.: Structural effects upon enzymatic hydrolysis of poly(butylene succinate-co-ethylene succinate)s. Macromolecules, 30, 7403-7407 (1997). DOI: 10.1021/ma970036k

[20] Yoo Y. T., Ko M. S., Han S. B., Kim T. Y., Im S., Kim D. K.: Degradation and physical properties of aliphatic copolyesters derived from mixed diols. Polymer Journal, 30, 538-545 (1998).

DOI: $10.1295 /$ polymj.30.538

[21] Gan Z., Abe H., Doi Y.: Crystallization, melting, and enzymatic degradation of biodegradable poly(butylene succinate-co-14 mol ethylene succinate) copolyester. Biomacromolecules, 2, 313-321 (2001).

DOI: $10.1021 / \mathrm{bm} 0056557$

[22] Gan Z., Abe H., Kurokawa H., Doi Y.: Solid-state microstructures, thermal properties, and crystallization of biodegradable poly(butylene succinate) (PBS) and its copolyesters. Biomacromolecules, 2, 605-613 (2001).

DOI: $10.1021 / \mathrm{bm} 015535 \mathrm{e}$

[23] Cao A., Okamura T., Nakayama K., Inoue Y., Masuda T.: Studies on syntheses and physical properties of biodegradable aliphatic poly(butylene succinate-coethylene succinate)s and poly(butylene succinate-codiethylene glycol succinate)s. Polymer Degradation and Stability, 78, 107-117 (2002).

DOI: 10.1016/S0141-3910(02)00124-6

[24] Zhu C. Y., Zhang Z. G., Liu Q. P., Wang Z. P., Jin J.: Synthesis and biodegradation of aliphatic polyesters from dicarboxylic acids and diols. Journal of Applied Polymer Science, 90, 982-990 (2003).

DOI: $10.1002 / a p p .12722$

[25] Montaudo G., Rizzarelli P.: Synthesis and enzymatic degradation of aliphatic copolyesters. Polymer Degradation and Stability, 70, 305-314 (2000).

DOI: 10.1016/S0141-3910(00)00139-7

[26] Ahn B. D., Kim S. H., Kim Y. H., Yang J. S.: Synthesis and characterization of the biodegradable copolymers from succinic acid and adipic acid with 1,4-butanediol. Journal of Applied Polymer Science, 82, 2808-2826 (2001).

DOI: 10.1002/app.2135

[27] Nikolic M. S., Djonlagic J.: Synthesis and characterization of the biodegradable poly(butylene succinateco-butylene adipate)s. Polymer Degradation and Stability, 74, 263-270 (2001).

DOI: $10.1016 / \mathrm{S} 0141-3910(01) 00156-2$

[28] Tserki V., Matzinos P., Pavlidou E., Vachliotis D., Panayiotou C.: Biodegradable aliphatic polyesters. Part I. Properties and biodegradation of poly(butylene succinate-co-butylene adipate). Polymer Degradation and Stability, 91, 367-376 (2006).

DOI: $10.1016 /$ j.polymdegradstab.2005.04.035

[29] Carothers W. H., Arvin J. A.: Studies on polymerization and ring formation. II. Poly-esters. Journal of the American Chemical Society, 51, 2560-2570 (1929). DOI: $10.1021 / \mathrm{ja} 01383 \mathrm{a} 042$
[30] Ranucci E., Liu Y., Lindblad M. S., Albertsson A-C.: New biodegradable polymers from renewable sources. High molecular weight poly(ester carbonate)s from succinic acid and 1,3-propanediol. Macromolecular Rapid Communications, 21, 680-684 (2000).

DOI: $10.1002 / 1521-3927(20000601) 21: 10<680:: A I D-$ MARC680>3.0.CO;2-Y

[31] Liu Y., Ranucci E., Lindblad M. S., Albertsson A. C.: New biodegradable polymers from renewable sources: Polyester-carbonates based on 1,3-propylene-co-1,4cyclohexanedimethylene succinate. Journal of Polymer Science Part A: Polymer Chemistry, 39, 25082519 (2001).

DOI: $10.1002 /$ pola.1227

[32] Bikiaris D. N., Papageorgiou G. Z., Achilias D. S., Pavlidou E., Stergiou A.: Miscibility and enzymatic degradation studies of poly(E-caprolactone)/poly(propylene succinate) blends. European Polymer Journal, 43, 2491-2503 (2007).

DOI: 10.1016/j.eurpolymj.2007.03.051

[33] Papageorgiou G. Z., Bikiaris D. N.: Synthesis, cocrystallization, and enzymatic degradation of novel poly (butylene-co-propylene succinate) copolymers. Biomacromolecules, 8, 2437-2449 (2007).

DOI: $10.1021 / \mathrm{bm} 0703113$

[34] Chen C-H., Peng J-S., Chen M., Lu H-Y., Tsai C-J., Yang C-S.: Synthesis and characterization of poly(butylene succinate) and its copolyesters containing minor amounts of propylene succinate. Colloid and Polymer Science, 288, 731-738 (2010).

DOI: $10.1007 / \mathrm{s} 00396-010-2187-9$

[35] Sullivan C. J., Dehm D. C., Reich E. E., Dillon M. E.: Polyester resins based upon 2-methyl-1,3-propanediol. Journal of Coatings Technology, 62, 37-45 (1990).

[36] Bello P., Bello A., Riande E.: Conformational characteristics and crystalline order in poly(2-methyl-1,3propane glycol terephthalate). Macromolecules, 32, 8197-8203 (1999).

DOI: $10.1021 / \mathrm{ma} 990485 \mathrm{f}$

[37] Nalampang K., Johnson A. F.: Kinetics of polyesterification: modelling and simulation of unsaturated polyester synthesis involving 2-methyl-1,3-propanediol. Polymer, 44, 6103-6109 (2003).

DOI: $10.1016 / \mathrm{S} 0032-3861(03) 00552-4$

[38] Suh J., Spruiell J. E., Schwartz S. A.: Melt spinning and drawing of 2-methyl-1,3-propanediol-substituted poly(ethylene terephthalate). Journal of Applied Polymer Science, 88, 2598-2606 (2003).

DOI: 10.1002/app.11871

[39] Lewis C. L., Spruiell J. E.: Crystallization of 2methyl-1,3-propanediol substituted poly(ethylene terephthalate). I. Thermal behavior and isothermal crystallization. Journal of Applied Polymer Science, 100, 2592-2603 (2006).

DOI: $\underline{10.1002 / a p p .22786}$ 
[40] Huang Y-J., Jiang W-C.: Effects of chemical composition and structure of unsaturated polyester resins on the miscibility, cured sample morphology and mechanical properties for styrene/unsaturated polyester/lowprofile additive ternary systems. 1: Miscibility and cured sample morphology. Polymer, 39, 6631-6641 (1998).

DOI: 10.1016/S0032-3861(98)00164-5

[41] Huang Y. J., Chen L. D.: Effects of chemical composition and structure of unsaturated polyester resins on the miscibility, cured sample morphology and mechanical properties of styrene/unsaturated polyester/lowprofile additive ternary systems: 2 . Mechanical properties. Polymer, 39, 7049-7059 (1998).

DOI: 10.1016/S0032-3861(98)00165-7

[42] Kharas G. B., Kamenetsky M., Simantirakis J., Beinlich K. C., Rizzo A-M. T., Caywood G. A., Watson K.: Synthesis and characterization of fumarate-based polyesters for use in bioresorbable bone cement composites. Journal of Applied Polymer Science, 66, 11231137 (1997).

DOI: 10.1002/(SICI)1097-4628(19971107)66:6<1123:: AID-APP13>3.0.CO;2-2

[43] Kharas G. B., Villaseñor G., Diener C. A., Baugh M., McColough K., Mikach S., Scola A., Whitesell J., Watson K.: Synthesis and characterization of fumarate copolyesters for use in bioresorbable bone cement compositions. Journal of Macromolecular Science Part A: Pure and Applied Chemistry, 43, 855-863 (2006). DOI: $10.1080 / 10601320600653582$

[44] Diakoumakos C. D., Jones F. N.: Studies on the chemical, physical and mechanical properties of high-solids clearcoats prepared from hydroxyl-terminated isophthalate-based oligoesters and a melamine resin. Surface and Coatings Technology, 140, 183-194 (2001). DOI: $\underline{10.1016 / \mathrm{S} 0257-8972(01) 01047-7}$
[45] Chen C-H., Lu H-Y., Chen M., Peng J-S., Tsai C-J., Yang C-S.: Synthesis and characterization of poly(ethylene succinate) and its copolyesters containing minor amounts of butylene succinate. Journal of Applied Polymer Science, 111, 1433-1439 (2009).

DOI: $10.1002 / a p p .29035$

[46] Yamadera R., Murano M.: The determination of randomness in copolyesters by high resolution nuclear magnetic resonance. Journal of Polymer Science Part A-1: Polymer Chemistry, 5, 2259-2268 (1967).

DOI: $10.1002 /$ pol.1967.150050905

[47] Newmark R. A.: Sequence distribution in polyethylene/tetramethylene terephthalate copolyesters by ${ }^{13} \mathrm{C}$ NMR. Journal of Polymer Science: Polymer Chemistry, 18, 559-563 (1980).

DOI: $\underline{10.1002 / p o l .1980 .170180216}$

[48] Ko C-Y., Chen M., Wang H-C., Tseng I-M.: Sequence distribution, crystallization and melting behavior of poly(ethylene terephthalate-co-trimethylene terephthalate) copolyesters. Polymer, 46, 8752-8762 (2005). DOI: $10.1016 /$ j.polymer.2005.01.107

[49] Tsai C-J., Chang W-C., Chen C-H., Lu H-Y., Chen M.: Synthesis and characterization of polyesters derived from succinic acid, ethylene glycol and 1,3-propanediol. European Polymer Journal, 44, 2339-2347 (2008). DOI: $10.1016 /$ j.eurpolymj.2008.05.002

[50] Backson S. C. E., Kenwright A. M., Richards R. W.: A ${ }^{13} \mathrm{C}$ n.m.r. study of transesterification in mixtures of poly(ethylene terephthalate) and poly(butylene terephthalate). Polymer, 36, 1991-1998 (1995). DOI: 10.1016/0032-3861(95)91443-B

[51] Alexander L. E.: X-ray diffraction methods in polymer science. Huntington, New York (1969). 